\title{
Trajetórias de vida: repercussões da maternidade adolescente na biografia de mulheres que viveram tal experiência
}

\author{
Janine Raymundi Esteves \\ Faculdade Brasileira - Univix \\ Paulo Rogério Meira Menandro \\ Universidade Federal do Espírito Santo
}

\begin{abstract}
Resumo
Parte do conhecimento disponível na sociedade sobre gravidez adolescente retrata-a como acontecimento marcante que repercute, inevitável e negativamente, na vida da jovem mãe. O trabalho investigou de que formas a maternidade adolescente interferiu na construção da biografia de mulheres que viveram tal processo. Foram entrevistadas 20 mulheres adultas, 10 de classe média e 10 de famílias de baixa renda, que engravidaram antes de completarem 18 anos, e cujos primogênitos têm entre 9 e 15 anos. Cada entrevista foi sintetizada em estruturas nas quais são destacadas informações essenciais sobre: (a) características socioeconômicas, culturais e familiares da entrevistada, de seu parceiro, e das respectivas famílias; (b) repercussões da gravidez e arranjos subseqüentes; (c) experiência da maternidade e interferências percebidas nos relacionamentos familiares e afetivos, nas atividades escolares e de lazer, e nos projetos de futuro; (d) vida conjugal. Os dados mostram que ocorreram repercussões de diversas modalidades, que nem sempre foram negativas e limitantes. A maior ou menor magnitude das repercussões decorre, fundamentalmente, das condições de inserção socioeconômica das famílias da mãe adolescente e de seu parceiro, e do contexto em que essas diferentes condições de inclusão e exclusão social ocorrem.

Palavras-chave: gravidez na adolescência; maternidade; suporte social
\end{abstract}

\begin{abstract}
Life paths: repercussions of adolescent motherhood on the biography of women who have lived this experience. Part of the knowledge available on teenage pregnancy pictures it as a defining event which influences, inevitably and negatively, the life of the young mother. This work investigated in what forms adolescent maternity has interfered in the construction of the biography of women who have lived this process. Twenty adult women were interviewed, 10 of them coming from middle-class and 10 from low-income families, who got pregnant before turning 18, and whose first-born are between 9 and 15 years old. Each interview was condensed in structures in which specific essential information are highlighted: (a) socio-economic, cultural and familial characteristics of the interviewee, of her partner, and their respective families; (b) pregnancy repercussions and subsequent arrangements; (c) motherhood experience and interferences perceived in familial and romantic relationships, in school and leisure activities, and in future projects; (d) conjugal life. The data show that repercussions occurred of different kinds, which were not always negative and limiting. The higher or lesser magnitude of the repercussions depends, fundamentally, of the socio-economic insertion condition of the families of the adolescent mother and her partner, and of the context in which these social inclusion and exclusion occur.
\end{abstract}

Keywords: adolescent pregnancy; motherhood; social support

$\mathrm{N}$ as últimas décadas, diversos temas ligados à vida do adolescente brasileiro (comportamento, interesses, saúde, entre outros) ganharam especial visibilidade tanto no âmbito das Ciências Humanas e Sociais como na área da Medicina e da Saúde Coletiva. Os registros disponíveis no Brasil revelam expressiva e crescente freqüência de ocorrências de gravidez adolescente. Das mulheres que tive- ram filhos nos doze meses que antecederam ao Censo de 2000, 20,33\% tinham entre 10 a 19 anos. Em 1996, segundo dados do DATASUS/FNS/MS, 25,79\% do total de partos realizados no Sistema Único de Saúde (SUS) foram em adolescentes entre 10 a 19 anos de idade. Associado a isso, há o declínio dos índices de gravidez em todas as faixas etárias, exceto entre mulheres de 15 a 19 anos. É evidente que, diante 
de tal questão, ganha ampla projeção a preocupação com o fenômeno, que passa a ser tratado como um problema social, constituindo-se, assim, em foco de preocupações e debates no campo da Saúde Pública, da Educação e da Psicologia.

Parte expressiva do conhecimento que circula na sociedade sobre gravidez adolescente trata tal ocorrência como acontecimento marcante que repercute, inevitável e negativamente, na continuidade da vida da jovem mãe, além de vêla como associada a um conjunto de implicações negativas (para o bebê, para a gestante/mãe ou para ambos) na esfera biomédica: maior risco de morbimortalidade da mãe e da criança, prematuridade, baixo peso do bebê ao nascer, restrição de crescimento intra-uterino, sofrimento fetal agudo intraparto, desproporção feto-pélvica, diabetes gestacional, anemia, retardo do desenvolvimento uterino, pré-eclâmpsia (Carvalho, Souza, Oliveira, \& Pires, 2002). Reis (1998) chama a atenção para o uso significativo, nos anos 1960, de termos como doença, enfermidade e epidemia no contexto da gravidez adolescente.

A gravidez/maternidade adolescente tem sido associada também a um conjunto de fatores de natureza psicossocial que afetam diretamente a vida do bebê (assistência pré-natal deficiente, maior incidência de patologias durante e após a gestação, maior chance de adoecerem, sofrerem acidentes e de apresentarem baixo rendimento escolar), ou da mãe (menor chance de completar a escolaridade, redução nas oportunidades de emprego, tendência maior à construção de famílias numerosas e de separações) (Coll, 2001; Gomes, Fonseca, \& Veiga, 2002; Oliveira, 1998; Ribeiro, Barbieri, Bettiol, \& Silva, 2000; Santos \& Schor, 2003; Yazlle et al., 2002).

Ao descreverem as interferências da gravidez no processo de adolescência e a forma pela qual a adolescente estrutura a ocorrência de gravidez em sua vida, em suas relações, em seu mundo subjetivo, alguns autores (por exemplo: Desser, 1993; Domingues \& Alvarenga, 1997; Monteiro, Cunha, \& Bastos, 1998) revelam tendência a descrever as decorrências de tal acontecimento como disrupção, concebendo a gravidez como interrupção e muitas vezes ponto final do processo adolescente, devido às implicações biológicas, psicológicas e socioeconômicas que traz. O pai adolescente é muito menos investigado e é pouco mencionado, e tal realidade não é específica do Brasil (Levandowski, 2001; Medrado \& Lyra, 1999; Reis, 1997; Trindade \& Menandro, 2002).

Entre as conseqüências da gravidez adolescente comumente mencionadas podem ser citadas: (a) impossibilidade de completar a função da adolescência, tendo que antecipar escolhas e abreviar experiências; (b) abandono da vida escolar (por vergonha, proibição ou interdição de outras naturezas); (c) menor chance de qualificação profissional, com óbvios reflexos para as oportunidades de inserção posterior no mundo do trabalho; (d) grande dificuldade para rearticular a vida sexual e limitar a fecundidade; (e) impossibilidade de estabelecer uma família com plena autonomia, autogestão e projeto de futuro; (f) dependência financeira absoluta da família ou do pai da criança; (g) maior risco de instabilidade conjugal; (h) abandono familiar da adolescente, em alguns casos, levando a maior empobrecimento da mesma e da família que venha a constituir; (i) vivência de preconceito em várias instâncias sociais; (j) despreparo para lidar com o desenvolvimento do filho; $(\mathrm{k})$ maior risco de comprometimento da saúde física e/ou emocional do bebê; (l) risco alto de comprometimento da saúde física e/ou emocional da mãe adolescente, diante das dificuldades enfrentadas no atendimento de suas próprias necessidades e carências. Completam tal quadro os aspectos biomédicos já mencionados.

Tem peso importante na construção de um quadro como esse a visão bastante difundida por algumas concepções originárias da própria Psicologia (também elas, hoje, grandemente reformuladas, mas ainda influentes em vários grupos profissionais ou culturais), segundo as quais a adolescência é um período de turbulência, de rebeldia, de inconseqüência, ou seja, é um problema. Se há adesão à idéia de que a própria adolescência já é, naturalmente, problemática, certamente resultará uma perspectiva que aceita com facilidade a visão de que uma gravidez em tal período agrava o problema.

Gomes et al. (2002) mostram que muitos dos dados que embasam alguns dos pontos de vista mencionados são controversos e associados com precária assistência pré-natal. Coll (2001) cita trabalhos que evidenciam que as adolescentes atendidas em programas especiais desde o início da gravidez, apresentam resultados perinatais iguais ou melhores que os de mulheres de mais idade. Santos e Schor (2003) destacam que vários pesquisadores criticam a visão que aqui está sendo comentada como reducionista e não aceitam o rótulo problema, considerado como abordagem limitante e que pode contribuir para expor as adolescentes a riscos adicionais.

Assim, freqüentemente, se omite ou não se dá importância à possibilidade da gravidez adolescente acontecer com jovens em diferentes contextos culturais, econômicos, familiares e poder alcançar jovens com diferentes idades, com diferentes condições de saúde e de desenvolvimento corporal, e com diferentes modalidades ou estágios de inserção escolar ou profissional. Além disso, pode envolver parceiros sexuais muito diversos quanto à maturidade pessoal, quanto ao projeto de vida futura e quanto à condição pessoal ou familiar ser ou não facilitadora do lidar com a gravidez e com o filho.

Catharino (2002) acrescenta que "a compreensão da ocorrência da gravidez na adolescência é muitas vezes obscurecida pelo discurso médico psicológico que, em consonância com ideais higienistas, vem historicamente se limitando a identificar causas para evitar conseqüências sociais indesejáveis” (p. 10). Assim, a gravidez adolescente, em função de julgamentos morais, é vista como um problema a ser resolvido de forma socialmente aceita. O corte abrupto imposto na vida da adolescente que engravida parece não decorrer da maternidade em si, mas da reação do grupo mais próximo à adolescente diante da gravidez/maternidade (Fávero \& Mello, 1997).

Steinberg e Morris (2001), em ampla revisão, destacam que a pesquisa sobre adolescência permanece fortemente marcada (há muitas décadas) pelas noções de que a adolescência é, inerentemente, um período de dificuldade, de que 
durante esta fase da vida o desenvolvimento problemático é mais revelador e típico do que o desenvolvimento em harmonia com as normas sociais, e de que o desenvolvimento adolescente saudável decorre mais da esquiva de problemas do que da aquisição e aprimoramento de competências.

A recusa a um termo como "problema” ao falar da gravidez adolescente exige um esclarecimento. Não há intenção de apologia à maternidade adolescente concebendo-a como acontecimento sem qualquer repercussão especial e defendida como opção boa ou desejável. São legítimas as preocupações da sociedade em relação à saúde da adolescente e de seu filho. A idéia é apenas alertar para o fato de que "a concepção negativa e reducionista sobre o problema da gravidez/maternidade na adolescência pode construir restrições e implicações conceituais no desenvolvimento de pesquisas e na atuação dos profissionais junto aos adolescentes" (Santos \& Schor, 2003, p. 22).

O presente estudo nasceu de uma inquietação com esse conjunto bastante difundido de concepções segundo as quais a gravidez e a maternidade adolescente resultam, inevitavelmente, em conseqüências catastróficas para quem as vive. Uma possibilidade investigativa que nos pareceu promissora foi a de trabalhar com uma perspectiva de distanciamento no tempo, buscando dados com mulheres que viveram a experiência da gravidez adolescente vários anos atrás, de forma que se possa constatar se essas supostas conseqüências catastróficas se confirmam. O objetivo do trabalho, portanto, foi o de identificar aspectos sociais, culturais, econômicos e familiares da vida da adolescente no momento em que ficou grávida e verificar que tipos de ocorrências se seguiram, de fato, à experiência da gravidez. Assim, pretendeu-se analisar o que significou para mulheres, que hoje são adultas, serem mãe e adolescente concomitantemente, ou seja, como este episódio afetou a biografia dessas pessoas, interferindo na construção de suas identidades.

\section{Método}

Participaram do estudo 20 mulheres que viveram a experiência da maternidade antes dos 18 anos, cujos primeiros filhos estavam com idades entre 9 a 15 anos na época da entrevista. $\mathrm{O}$ intervalo entre a gravidez e a entrevista permite aferir como se organizou a vida das entrevistadas nas esferas pessoal, conjugal, familiar e profissional, após a constatação da gravidez. Metade das entrevistadas vivia em famílias de classe média quando ocorreu a gravidez, e metade vivia em famílias de baixa renda; conforme local de residência, atividade profissional e/ou condição de estudante, e renda familiar da entrevistada.

As informações foram coletadas através de entrevistas baseadas em roteiro semi-estruturado, tendo natureza retroativa, e objetivando reconstituir o amplo conjunto de circunstâncias associadas à experiência da maternidade adolescente, enfatizando o suporte social disponível e a organização da vida dessa mãe adolescente durante a gravidez e nos anos seguintes ao nascimento da criança.
A coleta de dados foi realizada em local e horário escolhidos pelas entrevistadas, observando-se os indispensáveis dispositivos éticos previstos na legislação sobre pesquisas com seres humanos. As entrevistas, individuais, foram gravadas e posteriormente transcritas. Após a transcrição integral das entrevistas, procedemos à leitura do material utilizando a técnica de análise de conteúdo (Bardin, 1977; Krippendorf, 1980) para seleção, organização, análise e interpretação dos dados disponíveis nos relatos. Buscou-se ultrapassar o conteúdo manifesto na mensagem e construir inferências num processo interpretativo cuidadoso e fundamentado, caso a caso, reconstruindo os relatos de acordo com núcleos de significado apreendidos. Na comparação das diversas entrevistas buscou-se apreender regularidades e processos comuns relatados como parte da organização da vida dessas diferentes mulheres que engravidaram na adolescência.

Para a interpretação dos dados procurou-se identificar (ou reconstituir cronologicamente) alguns aspectos do contexto adolescente, características com que foi vivida a experiência da gravidez e da maternidade em tal período da vida, e aferir as características da avaliação feita pela entrevistada quanto às repercussões de tais experiências na estruturação de sua vida pós-gravidez.

As entrevistadas estão identificadas por nomes fictícios, iniciados com a letra A para aquelas de classe média (Adélia, Adriana, Abigail, Andressa, Alessandra, Alice, Amanda, Angélica, Alcione, Ana) e com a letra B para as de famílias de baixa renda (Bruna, Bianca, Beatriz, Betina, Brenda, Brunela, Betânia, Bartira, Berenice, Bárbara). Foram considerados alguns eixos centrais em torno dos quais as informações prestadas se articulam e que nortearão a seqüência de apresentação dos resultados. A saber:

Características prévias. Alguns aspectos sociais, culturais, econômicos e familiares da entrevistada e de seu parceiro, buscando reconstituir o contexto de ocorrência da gravidez e apreender particularidades e características dos relacionamentos e das atividades das entrevistadas, bem como seus repertórios de informações e experiências.

Gravidez. Repercussões da gravidez no ambiente familiar e em outros contextos freqüentados pela entrevistada, na época, enfatizando os sentimentos e preocupações, as possibilidades discutidas após confirmação da gravidez, as mudanças identificadas nos relacionamentos e nas atividades sociais, e as facilidades em termos de suporte financeiro e emocional.

Maternidade e vida pessoal após a gravidez. Interferências de qualquer natureza percebidas pela entrevistada que digam respeito às seguintes esferas de atividades: escolar, social, lazer, relacionamento com amigos e amigas, relacionamento com a própria família e com a do parceiro, novas relações afetivas e sexuais (quando for o caso), preparação para profissionalização, trabalho (quando for o caso). Saúde da entrevistada e do bebê. Identificação das pessoas percebidas como fontes de apoio e suporte financeiro, emocional, de orientação e de compartilhamento de atividades. 
Vida conjugal, nos casos em que tal condição chegou a ser vivida. Eventuais aspectos positivos e dificuldades.

Avaliação distanciada da própria gravidez adolescente. Concepção atual de maternidade e número de filhos. Dificuldades percebidas como relacionadas à maternidade adolescente. Avaliação das repercussões da experiência de maternidade adolescente no processo continuado de estruturação da vida afetiva, pessoal e profissional.

\section{Resultados e Discussão}

A idade de ocorrência de gravidez das entrevistadas variou entre 13 e 17 anos, sendo mais freqüentes ocorrências aos 16 anos (9 entrevistadas). De forma geral, os relatos confirmam a idéia de que o processo de adolescência não é vivido da mesma forma por todos os jovens (Minayo et al., 1999). As experiências adolescentes estão relacionadas às vicissitudes e possibilidades interpostas pelo contexto de inserção social.

Das entrevistadas do grupo baixa renda, nove não estavam estudando no período em que ficaram grávidas. Oito delas já exerciam atividades remuneradas e, muito provavelmente, tal fato está relacionado à inexistência de atividade escolar. Entre as entrevistadas do grupo classe média a situação é muito diferente: todas estudavam (uma delas havia concluído o ensino médio e se preparava para fazer uma seleção para emprego). Apenas uma tinha atividade remunerada concomitante com atividade escolar. Fica evidente que as condições de inserção socioeconômica atingiram as entrevistadas de cada grupo de forma diferenciada quanto às exigências de trabalho para colaborar com as despesas familiares (ou mesmo para manter-se) e quanto às condições para dedicar-se ao estudo. Tal fato apresenta-se associado à possibilidade da adolescente de gerir o futuro e planejar a própria vida (Ramos, 2002).

Identificou-se expressiva diferença na qualidade do relacionamento intrafamiliar entre os dois grupos de entrevistadas, o que sugere que alguns fatores associados à inserção socioeconômica precária da família dificultem o diálogo entre pais e adolescente e tornem menos eficiente o exercício de práticas de controle (ou de monitoramento, ou de acompanhamento) que não tenham características explicitamente invasivas ou autoritárias. Pode estar em jogo, ainda, eventual dificuldade dos pais, por limitações de escolarização e de acesso à informação, de estarem em sintonia com mudanças de padrões de comportamento aos quais os jovens aderem.

Segundo dezenove relatos, a gravidez foi conseqüência de relação sexual com parceiro conhecido, quase sempre parceiro fixo. Em relação à condição socioeconômica, entretanto, é possível constatar diferenças quanto à forma como o relacionamento é descrito pelas entrevistadas. No grupo classe média todos os episódios de gravidez são anteriores a qualquer tipo de formalização de união, o relacionamento é sempre descrito como namoro, sendo enfatizado o compromisso. Entre as entrevistadas de famílias de baixa renda são enunciadas diferentes classificações do tipo de compromis- so com o parceiro, que vão desde a definição de "namoro não muito sério" a um caso descrito como noivado e alguns de coabitação. Existe ainda o caso de Bruna, em que não havia relacionamento: a gravidez era decorrente de um estupro.

As diferenças entre os parceiros das adolescentes dos grupos classe média e baixa renda, em relação à sua condição de estudo e de trabalho são expressivas. No grupo baixa renda, nenhum dos parceiros estudava. No grupo classe média, sete parceiros estudavam (quatro deles em nível superior) e um já estava formado. Com relação ao trabalho, entre os parceiros das adolescentes do grupo baixa renda, oito tinham atividade remunerada (dois deles estavam desempregados), ainda que em alguns casos essa atividade tenha características de trabalho informal, como, por exemplo, vigiar carros. Nesse grupo, os dois que não trabalhavam estavam envolvidos com criminalidade. No grupo classe média, trabalhavam apenas os dois que não estavam estudando, o que já estava formado, e um dos sete que eram estudantes.

No que se refere às informações sobre métodos contraceptivos, todas as entrevistadas de classe média demonstraram conhecimentos prévios ("pílula”, “camisinha” e “coito interrompido"), mas apenas quatro delas (Adriana, Andressa, Alessandra e Amanda) utilizavam alguma estratégia para evitar a gravidez, classificada como acidental por todas as mulheres do grupo. A não utilização de estratégias de contracepção é justificada pela percepção de imunidade, pelo receio dos efeitos colaterais dos anticoncepcionais orais, pela dificuldade de acesso aos métodos, e pelo medo de que a mãe ou a família descobrisse a atividade sexual, vivenciada de forma clandestina e pouco planejada. Oliveira (1998) argumenta que a falta de informação sobre o próprio ciclo reprodutivo, somado aos resquícios do pensamento mágico infantil, leva a adolescente a concluir pela pouca ou nenhuma possibilidade de engravidar.

Entre as entrevistadas do grupo de baixa renda, apenas Beatriz, Betina, Betânia e Bárbara admitem informações prévias sobre métodos contraceptivos. A única que informou utilização de precaução para evitar a gravidez foi Beatriz, que tomava anticoncepcional oral, mas acredita que não o fazia corretamente devido ao desejo de engravidar. Bárbara também aponta o desejo de engravidar como fator determinante da não utilização de contraceptivos. As entrevistadas que mencionaram ter informações sobre métodos para evitar gravidez destacaram dificuldades no acesso aos mesmos, fazendo referências aos preços.

Entrevistadas de ambos os grupos mencionaram as dificuldades em abordar temas relacionados à sexualidade no ambiente familiar como tendo papel fundamental no desconhecimento de métodos anticoncepcionais ou no despreparo para sua utilização (Baldo \& Simões, 1999; Barros \& Carvalho, 2000; Santos Junior, 1999). A falta de informações e os temores quanto à reação familiar têm relação direta com a dificuldade de poder exercer atividade sexual de forma natural e planejada, o que poderia resultar em menos "acidentes" de todos os tipos. Ajuda a entender, também, porque as informações sobre sexo eventualmente disponíveis não são ade- 
quadamente incorporadas à vida cotidiana de muitas adolescentes, como destacam Baldo e Simões (1999).

Três das entrevistadas (Adélia, Adriana e Bianca) mencionaram que a gravidez resultou de sua primeira relação sexual. Outras seis entrevistadas declararam ter engravidado do primeiro parceiro sexual, mas não na primeira relação sexual. Todas as outras entrevistadas (onze no total) relataram experiência sexual anterior ao relacionamento com o parceiro na gravidez adolescente (com a óbvia exceção de Bruna, vítima de estupro).

No que se refere às reações e preocupações iniciais frente à descoberta da gravidez na adolescência, sete das entrevistadas do grupo de classe média (Andressa, Alessandra, Alice, Amanda, Angélica, Alcione, Ana) e três do grupo de baixa renda (Bruna, Betina e Bárbara) relataram preocupações relacionadas a como dar a notícia da gravidez aos pais ou equivalentes e a como seria a reação deles. Em ambos os grupos apareceram relatos de repercussão inicial positiva, relacionada ao caráter de realização que a maternidade representa.

As preocupações iniciais das grávidas adolescentes de classe média espalham-se por uma grande diversidade de aspectos: preocupação com a interferência da gravidez na manutenção de atividades escolares e na concretização dos projetos profissionais futuros (Adriana, Andressa, Angélica e Alcione); preocupações com as interferências da gravidez na manutenção de atividades de lazer associadas à adolescência (Abigail); sentimentos relacionados à suposição de interferência da gravidez no relacionamento e nas atividades com amigos (Adélia, Abigail, Andressa e Alessandra); percepção da gravidez como fator de aumento da dependência em relação aos pais (Amanda).

Entre as entrevistadas do grupo de baixa renda, fica evidente que, em função da inexistência de qualquer garantia de suporte financeiro, as preocupações iniciais das adolescentes de baixa renda concentravam-se na questão financeira, absolutamente proeminente, ou em outros temas diretamente vinculados a essa mesma questão.

Quase todas as entrevistadas de classe média relataram conhecimentos sobre tipos de parto. Das entrevistadas de baixa renda, seis admitiram inexistência de informação prévia sobre parto. O parto cesáreo ocorreu em apenas seis casos. Tal predominância de parto normal está sintonizada com as metas de incentivo ao parto normal e redução de cesarianas, adotadas pelos programas públicos de saúde. Apenas Bruna e Alice descreveram partos demorados, complicados e dolorosos.

Ao analisarem a repercussão da gravidez nos ambientes que freqüentavam, Adélia, Andressa, Betina, Brenda e Betânia admitiram terem sido alvo de críticas devido à idade em que engravidaram (registre-se que elas não eram as mais novas). Bruna, Beatriz, Brunela e Bárbara relataram que a gravidez repercutiu negativamente entre vizinhos e parentes. É possível dizer que, nas situações externas ao ambiente familiar, as repercussões foram mais negativas para as entrevistadas do grupo de baixa renda, que mencionaram com maior freqüência situações em que se sentiram discriminadas, sendo que, em dois casos (Bruna e Bartira), a adolescente foi expulsa de casa.
O nascimento do filho determina, para qualquer mulher, um conjunto de atividades e preocupações das quais é impossível eximir-se, e que têm impacto óbvio, urgência e prioridade superior a qualquer outra atividade. Portanto, determina, de início, uma nova rotina que é muito semelhante para todas as mães.

Foram freqüentes as menções ao fato de que a maternidade funciona como mecanismo quase automático de gerar mais responsabilidade e mais aumento de restrições relacionadas à disponibilidade do próprio tempo. As interferências relacionadas a horários foram particularmente destacadas por mulheres do grupo de classe média, em que adolescência parece ser percebida como uma fase descomprometida, de menos responsabilidade e maior flexibilidade.

Seis das entrevistadas de classe média interromperam os estudos após o nascimento da criança, mas apenas duas (Adélia e Ana) não o retomaram nos anos subseqüentes. As que mantiveram a atividade escolar só puderam fazê-lo em função de suporte de familiares que garantiam os cuidados com o bebê durante os seus horários de ausência. A única entrevistada de família de baixa renda (Betina) que estava estudando quando engravidou também interrompeu o estudo.

A questão do suporte em termos de compartilhar cuidados se coloca para as entrevistadas de famílias de baixa renda em relação à criação de condições que permitam o exercício de atividades remuneradas. Porém, muitas vezes, as pessoas que forneciam o apoio necessário (principalmente mãe e sogra) não podiam fazê-lo todo o tempo, pois também tinham atividades profissionais ou domésticas a cumprir, chegando mesmo a haver casos em que a jovem mãe não tinha com quem deixar o filho em caso de necessidade.

Não foi incomum o relato de que o suporte, no sentido de ficar com o bebê, para que a mãe adolescente pudesse ficar livre para outras atividades, era válido para o estudo ou o trabalho, mas não para atividades de lazer. A maior parte das entrevistadas reconhece que a necessidade de assumir as responsabilidades nos cuidados com a criança implica dedicação e compromissos que restringem a inserção e participação no contexto adolescente e nas atividades prazerosas a ele relacionadas.

Entrevistadas de ambos os grupos incluíram nas suas respostas sobre suspensão de atividades de lazer menções a dificuldades que estavam tendo com o parceiro, tais como: sentimentos de rejeição e abandono relacionados à diminuição do interesse sexual e ao fato do parceiro ter acesso a atividades sociais e de lazer enquanto elas permaneciam cuidando dos filhos.

Esse tema das dificuldades com o parceiro remete à questão das mudanças no próprio corpo, às transformações estéticas que a jovem mãe percebe em si mesma. A quase totalidade das entrevistadas avalia o próprio corpo antes da gravidez de forma positiva, mencionando práticas de cuidado pessoal e exercício de vaidades. O valor estético ser magra é especialmente destacado e desejado pelas entrevistadas do grupo de classe média, que mencionam preocupações com ginástica e exercícios físicos. Apenas Brenda, Betânia e Berenice se 
auto-avaliam de forma negativa, depreciativa, classificandose como feias ou descuidadas consigo antes da gravidez.

A maioria das entrevistadas percebe alterações significativas em suas características corporais após o processo de gestação e parto, ainda que a maior parte delas considere ter recuperado a forma física em pouco tempo. Muitas descrevem manutenção de práticas de autocuidado, embora com menos tempo para dedicar a tais tarefas. As que relatam terem se descuidado fazem clara associação com auto-estima reduzida em função do desinteresse do parceiro.

A experiência de amamentação foi incômoda, aversiva, e envolveu dor e desconforto, mas é visível o reconhecimento da importância da amamentação para a saúde e desenvolvimento dos filhos, assim como é claro o sentimento de que é um momento muito especial da ligação afetiva e de dependência entre mãe e filho.

Mesmo considerando o fato das entrevistadas terem sido mães adolescentes, não surpreende a constatação da presença viva da tradicional concepção, culturalmente construída ao longo de séculos, que vê a maternidade como o marco definitivo da realização feminina. Como ressalta Catharino (2002), não obstante os planos de estudo, trabalho e emancipação que são formulados na adolescência, o cotidiano ainda é regido por lógica de gênero que vincula maternidade e feminilidade.

Aparece com clareza nos relatos a idéia de que a atuação como mãe passou por um processo de aperfeiçoamento desde o início da maternidade, o que leva várias entrevistadas a assumirem que são, hoje, mães "melhores”.

A menor diferença de idade entre mãe e filha é aspecto tomado como positivo, ou porque a mãe, ainda jovem e muitas vezes já com outros filhos, pode ter ajuda em atividades domésticas e no cuidado com os filhos menores, ou porque a pequena diferença de idade possibilita maior sintonia com os filhos.

Um dos aspectos investigados foi o da percepção atual da entrevistada sobre sentir-se ou não preparada para a maternidade no momento em que engravidou. As entrevistadas, em sua maioria, reconhecem que não se sentiam preparadas para a maternidade, apontando as seguintes justificativas: despreparo ou inexperiência, no sentido de não dominar os cuidados a serem adotados com os filhos, nem conhecerem suas necessidades (Adélia, Angélica, Alessandra, Brenda, Berenice), falta de autonomia (Alice, Adélia, Abigail, Brunela), falta de infra-estrutura (Berenice), insegurança (Angélica, Brenda, Adriana), medo (Angélica), imaturidade e sentimentos associados à idade (Adriana, Beatriz, Abigail, Bartira, Berenice, Amanda). Betânia considera que não estava preparada e não cumpriu as funções de mãe, que ficaram delegadas à sua mãe. As demais avaliam que estavam preparadas para serem mães, justificando-se com o fato de terem experiência de cuidar de crianças pequenas ou argumentando terem desejo de ter filho. Algumas destacaram que estavam preparadas e que se sentiram seguras em função do suporte econômico fornecido pelo parceiro (Andressa) ou do apoio familiar (Alcione).
Entre as entrevistadas, apenas uma (Abigail) não passou a ter vida conjugal no período que vai da confirmação da gravidez até imediatamente após o nascimento da criança: trata-se de caso em que o parceiro não assumiu a paternidade e, morando em outra cidade, ignorou a gravidez, não tendo contato com o filho até hoje.

Diversas entrevistadas componentes do grupo de baixa renda já viviam situação de coabitação. Todas as outras casaram ou "juntaram”. Apenas três dessas uniões resultaram em separação, embora existam outros dois casos em que o parceiro morreu. Tanto aquelas que se separaram como as que ficaram viúvas voltaram a estabelecer relacionamentos afetivo-sexuais, com intervalo de tempo máximo de 2 anos.

Entre as entrevistadas do grupo de classe média, as separações foram mais freqüentes: cinco separações, sendo que quatro delas ocorreram com até 3 anos de convivência. Todas as que se separaram, mais a única que não casou, voltaram a estabelecer relacionamento afetivo-sexual com intervalo de tempo máximo de 2 anos.

É interessante comentar que a situação das entrevistadas dos dois grupos, em termos de quantidade de filhos que tiveram, é bastante diferente. As dez entrevistadas do grupo de baixa renda tiveram, ao todo, 39 filhos. Só uma delas teve apenas um filho (Bárbara), enquanto a recordista (Betânia) teve seis filhos. As entrevistadas do grupo de classe média tiveram, ao todo, 18 filhos (uma delas estava grávida). Quatro delas tiveram apenas um filho e as recordistas (Alice e Ana) tiveram três filhos.

Obviamente, a experiência da gravidez adolescente determinou transformações expressivas na vida das entrevistadas. É muito provável, por exemplo, que se fosse possível confrontar suas histórias de vida com as trajetórias de algumas das amigas com as quais conviviam no mesmo grupo de adolescentes, e que não tenham engravidado na mesma faixa etária, muitas diferenças poderiam ser encontradas em decorrência dos leques de opções serem diferentes nas duas situações.

A grávida adolescente é, quase sempre, uma grávida em situação de dependência total ou parcial de adultos tutores e, como destacou Coll (2001), continua sendo uma adolescente. Só esse fato já configura um arranjo inicial a partir do qual as decisões seguintes não poderão ser tomadas com autonomia pela própria adolescente e por seu parceiro, até mesmo por razões legais. Se o parceiro também é adolescente, as dificuldades se intensificam.

No que se refere aos planos e projetos de vida, os relatos das entrevistadas do grupo de classe média situam-se em três vertentes principais relacionadas entre si: (a) continuar a escolarização e alcançar a profissionalização em atividades que exigem formação universitária; (b) assegurar condições de desenvolvimento tão apropriadas quanto possível para seus filhos (e, até mesmo, ter outros filhos - afinal estamos falando de entrevistadas cuja idade está em torno de 30 anos); (c) ter a própria casa.

É evidente que a consolidação de projetos dessa natureza não foi automática e isenta de percalços. Muitas vezes o apoio da família, do parceiro, e da família do parceiro foi fun- 
damental para indicar o rumo e romper a perplexidade que acompanhava as rápidas mudanças vividas simultaneamente em momento em que os sinais não eram facilmente interpretáveis.

Adélia é a única das entrevistadas do grupo de classe média que não retomou atividades escolares e não fez referência a voltar a estudar como parte de seus planos. A outra entrevistada que não cursou faculdade, Ana, tem planos de estudar Psicologia - curso que, segundo ela, contribuiria para atividades que já exerce. As demais entrevistadas deram continuidade aos projetos escolares de adolescência, com eventuais alterações nos prazos para conclusão do curso ou inserção no mercado de trabalho, mas mantendo, de certa forma, o período de maior preparação e qualificação profissional que caracteriza os jovens de classe média.

No grupo de entrevistadas de baixa renda os projetos mencionados circulam em torno de quatro eixos relacionados entre si. Um deles, que é referência constante, é o da busca por emprego, para suprir necessidades de toda ordem, inclusive o sustento do bebê. Um segundo eixo é o do desejo de retomar as atividades escolares, o que aparece freqüentemente associado à busca de inserção profissional mais qualificada visando uma vida melhor para os filhos e para si. O terceiro eixo em torno do qual os projetos eram construídos é o de ter a própria casa. O quarto eixo é o empenho para que o filho tenha uma vida melhor. Como diz Paiva (1996), os projetos das mães de famílias de baixa renda para seus filhos parecem uma tentativa de reparar a falta de cidadania: "o filho representa a possibilidade de um futuro melhor em que vai ter o que os pais não tiveram” (p. 221).

É evidente que os planos de cada um são redimensionados permanentemente em função de suas possibilidades. Ainda assim é importante destacar que as entrevistadas foram extremamente concordantes ao afirmarem que seus projetos foram realizados ou estão se realizando. Talvez isso possa ser interpretado no sentido de que a gravidez na adolescência obrigou uma redefinição de projetos, mas não impediu sua realização, sendo o apoio familiar destacado como importante para tal adaptação.

\section{Considerações finais}

Melucci (1997) argumenta que é na adolescência que é vivida de forma mais incisiva a experiência de dar sentido às próprias ações, estabelecendo conexões, freqüentemente provisórias, entre tempos, planos, limites, grupos, eventos internos, e as inúmeras possibilidades (reais ou simbólicas) que cada uma dessas esferas parcialmente sobrepostas proporciona.

A gravidez/maternidade na adolescência parece tornar a biografia de quem a vive mais previsível (dentro dos constrangimentos sociais que delimitam as possibilidades objetivas do grupo em que ela esteja inserida). A adolescente grávida não mais pode continuar a construir sua experiência de forma mais e mais fragmentada. Para Melucci (1997), os adolescentes pertencem a uma pluralidade de redes e de grupos, e entrar e sair dessas diferentes formas de participação é mais rápido e mais freqüente do que antes. A quantidade de tempo que os adolescentes investem em cada uma dessas formas de participação é reduzida e tal possibilidade é que passa a estar parcialmente interditada para a adolescente grávida. Mais uma vez recorrendo a Melucci (1997), retomamos a seguinte afirmação:

A unidade e a continuidade da experiência individual não podem ser encontradas em uma identificação fixa com um modelo, grupo ou cultura definidos. Devem, ao invés disso, serem baseadas na capacidade anterior de mudar a forma de redefinirse a si mesmo repetidas vezes no presente, revertendo decisões e escolhas. (p. 11)

Não é mais possível para a adolescente grávida (assim como para qualquer outra grávida) reverter algumas decisões e escolhas, mas ela continua o processo de construção permanente da sua identidade sociocultural, o processo de redefinir-se a si mesma, repetidas vezes, em um presente que agora incorpora novos elementos. Adquirir identidade adulta pode ser entendido como, sendo reflexivo e aprendendo continuamente a aprender, desenvolver a capacidade continuada de produzir nova identidade, integrando passado e presente, na unidade e na continuidade de uma biografia individual. Ora, esse processo é o mesmo que está em jogo na adolescência, mesmo considerando inevitáveis diferenças contextuais. O processo de construção da identidade do indivíduo é um só, ainda que as circunstâncias específicas de sua vida cotidiana e de sua inserção social, econômica e cultural resultem em diversas configurações e matizes.

Talvez o aspecto mais proeminente dos dados que relatamos seja a constatação de que as características de inserção socioeconômica aparecem associadas com diferenças marcantes nas características das repercussões da gravidez adolescente. Tal constatação sugere que as repercussões de uma gravidez adolescente não devem ser pensadas, exclusivamente, a partir do conjunto de exigências e responsabilidades impostas a quem a vivencia, exigindo a compreensão de como características do contexto cultural e socioeconômico em que a família (ou similar) da grávida está imersa modulam tais repercussões.

Tal modulação apresentou-se como sendo de forte determinação em relação aos aspectos fundamentais para a inserção social: escolarização e trabalho. Dez ou mais anos após a gravidez adolescente, todas as entrevistadas de famílias de baixa renda, continuam vivendo em famílias (a mesma de origem ou a sua própria família, com cônjuge e filhos) que permanecem sendo de baixa renda, o que as torna, de forma agravada (pelo alto número de filhos, pelas dificuldades de trabalhar, pelos reflexos negativos que a ignorância e a defasagem na compreensão da realidade social têm sobre a formação dos filhos), protagonistas de um evidente processo de exclusão. Para as entrevistadas de famílias de classe média a situação é bem diferente: todas continuam sendo de classe média, e isso contribui de forma decisiva para a retomada e consecução de projetos que as torna protagonistas de uma 
vida marcada pelo exercício da cidadania. Mecanismos que poderiam ser descritos como de resiliência familiar atuam no sentido de superar os impasses e permitir que "tudo se ajeite”, com maior ou menor bem estar ou carências. Esses mecanismos de resiliência, entretanto, não conseguem, sozinhos, gerar condições para que as fronteiras impostas pela situação de inserção cultural e econômica sejam ultrapassadas.

Mesmo reconhecendo o conjunto de dificuldades associadas com uma gravidez adolescente, qualquer que seja a adolescente focalizada, o problema fundamental, certamente, é a desigualdade socioeconômica, e não a eventual gravidez adolescente. A redução de tal desigualdade resultaria em ampliação generalizada do acesso à informação, aumento do nível de escolarização, abertura e democratização das relações familiares, melhoria nas condições de saúde, maior diversidade de projetos pessoais com real viabilidade, e crescimento da segurança social e psicológica para todos, o que teria inevitáveis efeitos no sentido de transformar o fenômeno da gravidez adolescente de questão de grande impacto público em ocorrência eventual de natureza privada.

\section{Referências}

Baldo, T. R. F., \& Simões, M. J. S. (1997). Caracterização das gestantes adolescentes no município de Araraquara, São Paulo. Revista de Ciências Farmacêuticas, 20, 155-169.

Bardin, L. (1977). Análise de Conteúdo. Lisboa: Edições 70.

Barros, S. M. O., \& Carvalho, G. M. (2000). Fatores psicossociais relacionados à gravidez na adolescência. Acta Paulista de Enfermagem, 13(1), 9-17.

Carvalho, M. A. B. D., Souza, D. V., Oliveira, D. S., \& Pires, L. P. M. (2002). Gravidez na adolescência: aspectos socioeconômicos. Revista de Ginecologia e Obstetrícia Atual, 8(1), 7-14.

Catharino, T. R. (2002). Da gestão dos riscos à invenção do futuro: considerações médico-psicológicas e educacionais sobre histórias de meninas que engravidaram entre 10 e 14 anos. Tese de Doutorado não-publicada, Instituto de Psicologia, Universidade de São Paulo, São Paulo.

Coll, A. (2001). Embarazo en la adolescencia: cual es el problema? In S. D. Burak (Org.), Adolescencia y juventud en América Latina. Cartago (Costa Rica): Libro Universitário Regional.

DATASUS. (1996). Banco de dados do Sistema Único de Saúde. Disponível em: http:///www.datasus.gov.br. Acesso dia 01 de junho de 2003.

Desser, N. A. (1993). Adolescência: sexualidade e culpa. Rio de Janeiro: Rosa dos Tempos.

Domingues, C. M. A. S., \& Alvarenga, A. T. (1997). Identidade e sexualidade no discurso adolescente. Revista Brasileira de Crescimento e Desenvolvimento Humano, 7(2), 32-68.

Fávero, M. H., \& Mello, R. M. (1997). Adolescência, maternidade e vida escolar: a difícil conciliação dos papéis. Psicologia: Teoria e Pesquisa, 13(1), 131-136.
Gomes, R., Fonseca, E. M. G. O., \& Veiga, A. J. M. O. (2002). A visão da pediatria acerca da gravidez na adolescência: um estudo bibliográfico. Revista Latino-Americana de Enfermagem, 10(3), 408-414.

Krippendorff, K. (1980). Content Analysis: an introduction to its methodology. Newbury Park: Sage.

Levandowski, D. C. (2001). Paternidade na adolescência: uma breve revisão da literatura internacional. Estudos de Psicologia, 6(2), 195-209.

Medrado, B., \& Lyra, J. (1999). A adolescência desprevenida e a paternidade adolescente: uma abordagem geracional e de gênero. In N. Schor, M. S. F. T. Mota \& V. C. Branco (Orgs.), Cadernos Juventude, Saúde e Desenvolvimento (pp. 230-248). Brasília: Ministério da Saúde.

Melucci, A. (1997). Juventude, tempo e movimentos sociais. Revista Brasileira de Educação, 6-7, 5-14.

Minayo, M. C. S., Assis, S. G., Souza, E. R., Njaine, K., Deslandes, S. F., Silva, C. M. F. P., Fraga, P. C. P., Gomes, R., Abramovay, M., Waiselfisz, J. J., \& Monteiro, M. C. (1999). Fala galera: juventude, violência e cidadania na cidade do Rio de Janeiro. Rio de Janeiro: Garamond.

Monteiro, D. L. M., Cunha, A. A., \& Bastos, A. C. (1998). Gravidez na adolescência. Rio de Janeiro: Revinter.

Oliveira, M. W. (1998). Gravidez na adolescência: dimensões do problema. Cadernos CEDES, 19(45), 48-70.

Paiva, V. (1996). Sexualidades adolescentes: escolaridade, gênero e o sujeito social. In R. Parker \& R. M. Barbosa (Orgs.), Sexualidades brasileiras (pp. 216-235). Rio de Janeiro: Relume Dumará / ABIA / IMS-UERJ.

Ramos, F. P. (2002). Inserção laboral: impactos na identidade e nas relações sociais de adolescentes carentes. Dissertação de Mestrado não-publicada, Universidade Federal do Espírito Santo, Vitória.

Reis, A. O. A. (1997). Opacidade e visibilidade da paternidade na reprodução adolescente. Revista Brasileira de Crescimento e Desenvolvimento Humano, 7(2), 69-76.

Reis, A. O. A. (1998). Análise metafórico-metonímica do processo de constituição do pensamento da saúde pública acerca da adolescente grávida: os anos 60. Cadernos de Saúde Pública, 14(1), 115-123.

Ribeiro, E. R. O., Barbieri, M. A., Bettiol, H., \& Silva, A. A. M. (2000). Comparação entre duas coortes de mães adolescentes em município do Sudeste do Brasil. Revista de Saúde Pública, 34(2), 136-142.

Santos Júnior, J. D. (1999). Fatores etiológicos relacionados à gravidez na adolescência: vulnerabilidade à maternidade. In N. Schor, M. S. F. T. Mota \& V. C. Branco (Orgs.), Cadernos Juventude, Saúde e Desenvolvimento (pp. 223-229). Brasília: Ministério da Saúde.

Santos, S. R., \& Schor, N. (2003). Vivências da maternidade na adolescência precoce. Revista de Saúde Pública, 37(1), 15-23.

Steinberg, L., \& Morris, A. S. (2001). Adolescent development. Annual Review of Psychology, 52, 83-110.

Trindade, Z. A., \& Menandro, M. C. S. (2002). Pais adolescentes: vivência e significação. Estudos de Psicologia, 7(1), 15-23.

Yazlle, M. E. H. D., Mendes, M. C., Patta, M. C., Rocha, J. S. Y., Azevedo, G. D., \& Marcolin, A. C. (2002). A adolescente grávida: alguns indicadores sociais. Revista Brasileira de Ginecologia e Obstetrícia, 24(9), 609-614.

Janine Raymundi Esteves, mestre em Psicologia pela Universidade Federal do Espírito Santo, é professora de Psicologia do Desenvolvimento e da Adolescência na Faculdade Brasileira - UNIVIX (Vitória, ES). Endereço para correspondência: Rua Leopoldo Siqueira, 104; (Morada de Camburi); Vitória, ES. CEP: 29.075-110. Tel.: (27) 3327-9705. Fax: (27) 3228-1370. E-mail: janineresteves@uol.com.br

Paulo Rogério Meira Menandro, doutor em Psicologia Experimental pela Universidade de São Paulo, é professor no departamento de Psicologia Social e do Desenvolvimento e do Programa de Pós-Graduação em Psicologia da Universidade Federal do Espírito Santo. E-mail: paulomenandro@uol.com.br 